\title{
Two consecutive magneto-structural gas-solid transformations in non-porous molecular materials
}

\author{
Julia Miguel-Donet, ${ }^{[\mathrm{a}]}$ Javier López-Cabrelles, ${ }^{[\mathrm{a}]}$ Néstor Calvo Galve,${ }^{[\mathrm{a}]}$ Eugenio Coronado, ${ }^{[\mathrm{a}]}$ Guillermo \\ Mínguez Espallargas*[a]
}

\begin{abstract}
Modification of the magnetic properties in a solid-state material upon external stimulus has attracted much attention in the recent years for their potential applications as switches and sensors. Within the field of coordination polymers, gas sorption studies typically focus on porous solids, with the gas molecules accommodating in the channels. Here we present a 1D non-porous coordination polymer capable of incorporating $\mathrm{HCl}$ gas molecules, which not only causes a reordering of its atoms in the solid state but also provokes dramatic changes in the magnetic behaviour. Subsequently, a further solid-gas transformation can occur with the extrusion of $\mathrm{HCl}$ gas molecules causing a second structural rearrangement which is also accompanied by modification in the magnetic path between the metal centres. Unequivocal evidence of the two-step magnetostructural transformation is provided by $\mathrm{X}$-ray single-crystal diffraction.
\end{abstract}

\section{Introduction}

The rapid development of metal-organic frameworks (MOFs) ${ }^{[1]}$ since their emergence some 30 years ago, ${ }^{[2,3]}$ with over 70.000 structures already reported, ${ }^{[4]}$ have resulted in a vastly studied type of crystalline materials with applications in many diverse fields. Some MOFs show interesting dynamic behavior that can be triggered with external stimuli. ${ }^{[5]}$ These perturbations can modify the physical property of the MOF, thus opening the possibility to their application as switches and molecular sensors. ${ }^{[6]}$ Indeed, it has been shown that even the weak interaction between a gas molecule and a magnetic framework presenting spin-crossover can serve to tune its transition temperature with a proper rational design. ${ }^{[7-10]}$ However, the design of materials where porosity and cooperative magnetism coexist still remains a challenging issue, as these two properties are antagonistic: the former is typically facilitated by large linkers whereas the latter requires short distances between the spin carriers, albeit different successful synthetic approaches have been used in order to prepare porous magnetic materials. ${ }^{[11]}$

In addition, crystals of nonporous molecular materials have also been reported to show crystalline solid transformations through chemical reactions with gases despite the difficulty of maintaining crystallographic cohesion. ${ }^{[12]}$ In fact, it has even been reported the structural determination of an intermediate phase during a chemical

[a] J. Miguel-Donet, J. López-Cabrelles, N. Calvo Galve, Prof. E. Coronado, Dr. G. Mínguez Espallargas

Instituto de Ciencia Molecular (ICMol)

Universitat de València

c/ Catedrático José Beltrán 2, 46980 Paterna (Spain)

E-mail: guillermo.minguez@uv.es transformation in a non-porous molecular solid. ${ }^{[13,14]}$ We recently demonstrated that the combination of cooperative magnetism and gas sorption can be easily achieved through the use of nonporous materials able to incorporate the gas molecules into its framework, thus alleviating the necessity of large pores. ${ }^{[15]}$ This approach has subsequently been successfully applied to other systems. ${ }^{[16-18]}$ In these magnetic crystalline materials, the desired long structural order is preserved despite the rearrangement suffered, including cleavage and formation of covalent bonds, albeit the single crystal nature of the solid is typically lost, thus resulting in polycrystalline powders. Indeed, magnetic materials with structures unequivocally characterized by single-crystal diffraction after a chemical reaction are tremendously valuable for understanding the mechanism of the transformation and the magnetostructural correlations, but are extremely scarce. ${ }^{[13,19-28]}$ Here we present for the first time a two-consecutive guest inclusionrelease process occurring with retention of long-range order that is accompanied by modification in the magnetic behavior. The first process involves a polymeric-to-molecular material transformation, whereas the second process encompasses the reformation of a coordination polymer, as evidenced by X-ray single-crystal diffraction.

\section{Results and discussion}

The controlled diffusion of methanolic solutions of imidizadole (imH) and $\mathrm{CuCl}_{2} \cdot 2 \mathrm{H}_{2} \mathrm{O}$ in the presence of $\mathrm{NEt}_{3}$ produces dark blue laminateshape crystals of formula $\left[\mathrm{Cu}(\mathrm{im})(\mathrm{Cl})(\mathrm{imH})_{2}\right](1)$ as a single-phase crystalline compound. Crystallographic analysis reveals that compound 1 is composed of straight one-dimensional chains that run parallel to the crystallographic $b$-axis (Figure 1), as previously reported. ${ }^{[29,30]}$ The $\mathrm{Cu}$ centers present a distorted square pyramidal pentacoordinated structure, with the basal plane formed by $4 \mathrm{~N}$ atoms and $\mathrm{a} \mathrm{Cl}$ atom in the apical position. These metal centers are connected via the imidazolate ligands ( $\mathrm{im}^{-}$), forming $\mathrm{N}-\mathrm{C}-\mathrm{N}$ bridges, where the imidazolate is acting as a bidentate ligand (Figure 1). The $\mathrm{Cu}-\mathrm{N}$ distances of bridging imidazolate ligands are 1.956(3) and 1.970(3) $\AA$. The coordination sphere of the copper center is completed with three terminal ligands, a chloride in the apical position $(\mathrm{Cu}-\mathrm{Cl}$ : 2.5453(9) $\AA$ ) and two crystallographically related imidazole ligands on the equatorial position (Cu-N: 2.058(2) $\AA$ ). 


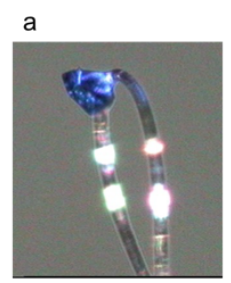

\section{b}
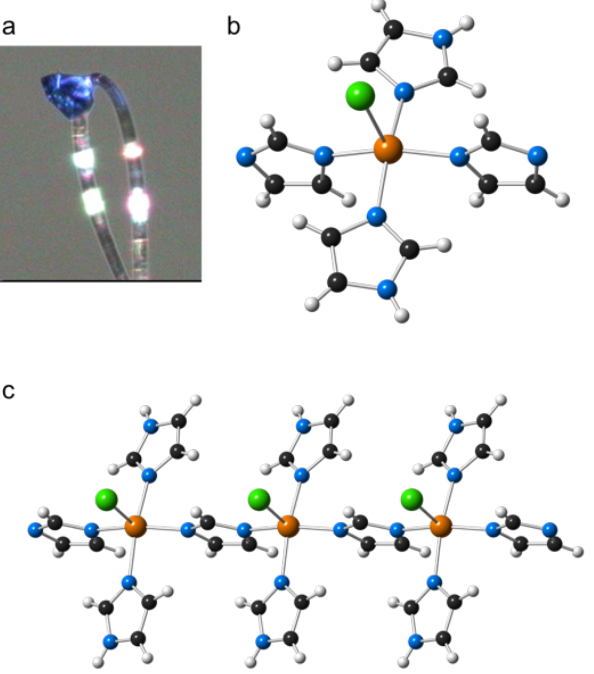

Figure 1. (a) Single crystal used for structural characterization. (b) Crystal structure of $\left[\mathrm{Cu}(\mathrm{im})(\mathrm{Cl})(\mathrm{imH})_{2}\right](1)$, depicting the square-based pyramidal geometry of the $\mathrm{Cu}^{\prime \prime}$ centre, with two $\mathrm{im}^{-}$ligands, two $\mathrm{imH}$ ligands, and one $\mathrm{Cl}$. (c) One dimensional chain propagated by the imidazolate ligands. $\mathrm{Key}: \mathrm{Cu}$, orange; $\mathrm{Cl}$, green; $\mathrm{N}$, blue; $\mathrm{C}$, black; $\mathrm{H}$, white.

The exposure of 1 to $\mathrm{HCl}$ vapors is accompanied by a change of color of the crystals, that starts in seconds, from blue (compound $\mathbf{1}$, see Figure 1a) to yellow (compound 2, see Figure 2a), indicative of a change in the coordination environment of the $\mathrm{Cu}$ centres, as previously observed. ${ }^{[15,17,31-37]}$ The process is completed in 0.5 hours. Despite the many structural modifications that occur upon the adsorption of the gas molecules, we have been able to isolate a single-crystal and solve the structure by $\mathrm{X}$-ray single-crystal diffraction, revealing that $\mathbf{2}$ is composed by distorted tetrahedral $\left[\mathrm{CuCl}_{4}\right]^{2-}$ anions and $\left[\mathrm{imH}_{2}\right]^{+}$cations, resulting in a nonporous molecular material of formula $\left(\mathrm{imH}_{2}\right)_{2}\left[\mathrm{CuCl}_{4}\right]$, also accessible through conventional synthetic routes. ${ }^{[38]}$ Three molecules of $\mathrm{HCl}$ are incorporated to the crystal structure of $\mathbf{1}$ whereas one imidazole ligand is released as amorphous imidazolium chloride (Figure S1). In fact, upon exposure of blue crystals of 1 to vapours of $\mathrm{HCl}$, it can be observed that the converted yellow crystals are surrounded by an oily phase, likely The chemisorption process involves the protonation of one imidazolate and one imidazole ligands of 1 , with cleavage of the covalent bonds of the gas molecules $(\mathrm{H}-\mathrm{Cl})$ and the $\mathrm{Cu}-\mathrm{N}$ coordination bonds of 1 , and formation of new $\mathrm{Cu}-\mathrm{Cl}$ and $\mathrm{N}-\mathrm{H}$ covalent bonds. Furthermore, the geometry around the $\mathrm{Cu}$ centers changes from square pyramidal to distorted tetragonal, with $\mathrm{Cu}-\mathrm{Cl}$ distances in the range 2.2423(13)2.2738(15) $\AA$ (Figure 2b). The discrete entities of 2 form a segregated hydrogen bonded network via $\mathrm{N}-\mathrm{H} \cdots \mathrm{Cl}$ hydrogen bonds, in the range 2.290-2.751 $\AA$, involving all the $\mathrm{N}-\mathrm{H}$ groups of the $[\mathrm{HimH}]^{+}$cations (Figure 2c). ${ }^{[39]}$ Although we cannot discard a dissolution/recrystallization process, ${ }^{[40,41]}$ this is very unlikely as the conversion $1 \rightarrow 2$ also takes place using dry $\mathrm{HCl}$, i.e. in a water free environment.

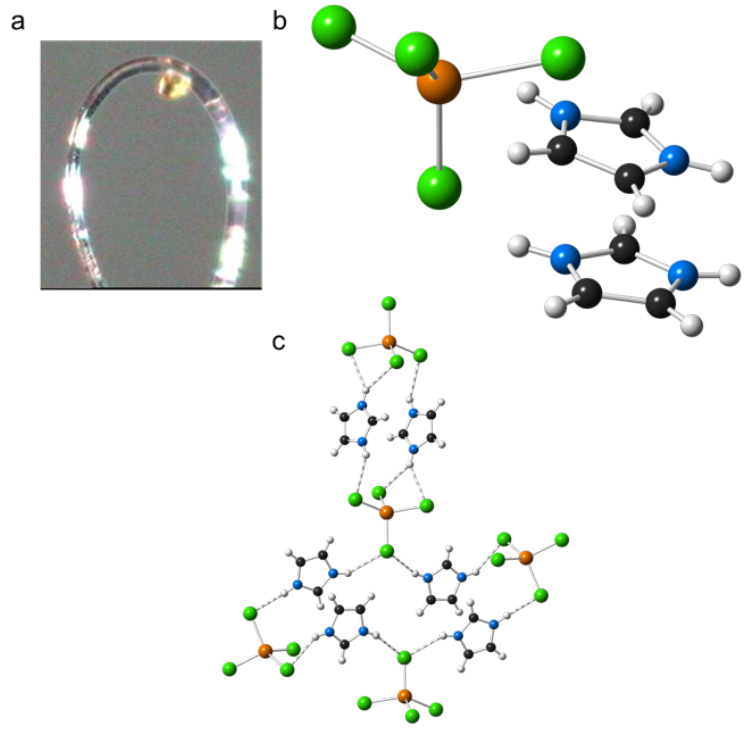

Figure 2. (a) Single crystal used for structural characterization. (b) Crystal structure of $\left(\mathrm{imH}_{2}\right)_{2}\left[\mathrm{CuCl}_{4}\right]$ (2). (c) Hydrogen bonded network propagated via $\mathrm{N}$ $\mathrm{H} \cdots \mathrm{Cl}$ hydrogen bonds. Key: $\mathrm{Cu}$, orange; $\mathrm{Cl}$, green; $\mathrm{N}$, blue; $\mathrm{C}$, black; $\mathrm{H}$, white. Dotted lines represent hydrogen bonds.

When $\mathbf{2}$ is exposed to air at room temperature, a second transformation takes place in the solid state, with the release of two equivalents of $\mathrm{HCl}$ from the structure, causing a further rearrangement of the molecular solid with an additional change of colour to pale green (compound 3, see Figure 3a). Importantly, this release of $\mathrm{HCl}$ occurs spontaneously, i.e. there is no need of vacuum, heat or additional stimuli to promote the loose of $\mathrm{HCl}^{[38,42-46]}$ although it is a slow process that can take several weeks to be complete; nevertheless, the release can be accelerated by heating. This process is reversible; thus, upon exposing 3 to $\mathrm{HCl}$ vapors (either vapours of concentrated aqueous solution of $\mathrm{HCl}$, or dry $\mathrm{HCl}$ ), compound 2 is also obtained. After desorption process of compound $\mathbf{2}$, we have been able to isolate a green single crystal of compound $\mathbf{3}$ that allowed us to solve its crystal structure, which reveals that $\mathbf{3}$ is composed of neutral trans$\left[\mathrm{CuCl}_{2}(\mathrm{imH})_{2}\right]$ units ${ }^{[47]}$ in which the imidazolium cations present in 2 have been deprotonated yielding neutral ligands that coordinate the $\mathrm{Cu}$ atoms in 3. This process involves the release of two equivalents of $\mathrm{HCl}$, with cleavage of $\mathrm{Cu}-\mathrm{Cl}$ and $\mathrm{N}-\mathrm{H}$ bonds, and formation of new $\mathrm{Cu}-\mathrm{N}$ bonds. The $\mathrm{Cu}$ centres have suffered a second change of geometry to adopt a trans square-planar geometry coordinated by two nitrogen atoms from $\mathrm{imH}(\mathrm{Cu}-\mathrm{N}: 1.961(4) \AA)$ and two chloride ligands (Cu-Cl: 2.321(2) $\AA$ and 2.357(2) $\AA$ ) (Figure 3b). One of these chloride ligands forms a weak apical interaction with the copper atom of a neighboring complex ( $\mathrm{Cu}-\mathrm{Cl} \cdots \mathrm{Cu}$ distance of 2.738(2) $\AA$ ), thus forming a one-dimensional chain along the $c$-axis (Figure $3 c$ ). The terminal chloride ligand interacts with two adjacent trans$\left[\mathrm{CuCl}_{2}(\mathrm{imH})_{2}\right]$ units by $\mathrm{N}-\mathrm{H} \cdots \mathrm{Cl}$ hydrogen bonds (2.449 and $2.631 \AA$ ). 

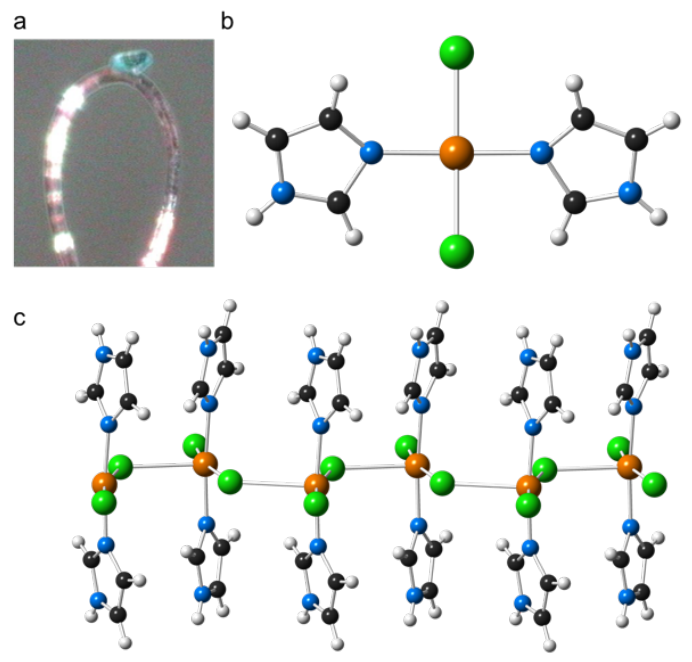

Figure 3. (a) Single crystal used for structural characterization. (b) Crystal structure of trans-[C $\left.\mathrm{CuCl}_{2}(\mathrm{imH})_{2}\right](3)$ depicting the square geometry of the $\mathrm{Cu}^{\prime \prime}$ centre, with two imH ligands and two $\mathrm{Cl}$. (c) One dimensional chain propagated by the $\mathrm{Cl}$ ligands. Key: $\mathrm{Cu}$, orange; $\mathrm{Cl}$, green; N, blue; $\mathrm{C}$, black; $\mathrm{H}$, white.

Imidazolate ligands are short organic ligands known to facilitate the presence of magnetic exchange when deprotonated, ${ }^{[48]}$ as it has been evidenced in the nonporous coordination polymer 1 (vide infra). Given the remarkable concerted rearrangement of covalent bonds that occurs during the $\mathrm{HCl}$ sorption/desorption involving this ligand, it is expected that changes in the magnetic properties accompany these transformations. The short $\mathrm{Cu}-\mathrm{NCN}-\mathrm{Cu}$ pathway between the copper centers in 1 facilitates the magnetic exchange between the metal centres, as evidenced in the plot of the molar magnetic susceptibility $\left(\chi_{M}\right)$ as a function of the temperature (Figure 4$)$ as well as in the thermal variation of the product of the molar magnetic susceptibility and temperature $\left(\chi_{M} T\right)$. The room temperature value of $\chi_{M} T$ of compound 1 has a value of $0.43 \mathrm{emu} \cdot \mathrm{K} \cdot \mathrm{mol}^{-1}$ which corresponds well with the expected value for non-interacting $\mathrm{Cu}^{2+}$ ions with spin $1 / 2$ and $g=2.15$. Upon cooling the system, the $\chi_{M} T$ product decreases (Figure $\mathrm{S} 2$ ), evidencing the existence of strong antiferromagnetic $\mathrm{Cu}-\mathrm{Cu}$ interactions, as it can be better observed in the $\chi_{M} v s$. T curve which exhibits a broad maximum at $68 \mathrm{~K}$. Modelling of the magnetic data has been performed using a model for a linear antiferromagnetic chain of $\operatorname{spin}=1 / 2$. This fit leads to a magnetic coupling $J=-79.1 \mathrm{~cm}^{-1}$ (Figure 4).

Major changes in the magnetic properties take place upon $\mathrm{HCl}$ chemisorption as a consequence of the structural changes, which modify the magnetic exchange paths between the $\mathrm{Cu}$ centres as well as the coordination geometry. Specifically, the $\mathrm{HCl}$ chemisorption of compound 1 causes the total protonation of the ligands, thus breaking the efficient magnetic pathway found in 1 . This structural rearrangement implies a change in the dimensionality of the material, from the 1D polymeric structure of 1 to the discrete molecular units in 2 being composed by tetrahedral $\left[\mathrm{CuCl}_{4}\right]^{2-}$ anions and $\left[\mathrm{imH}_{2}\right]^{+}$cations.
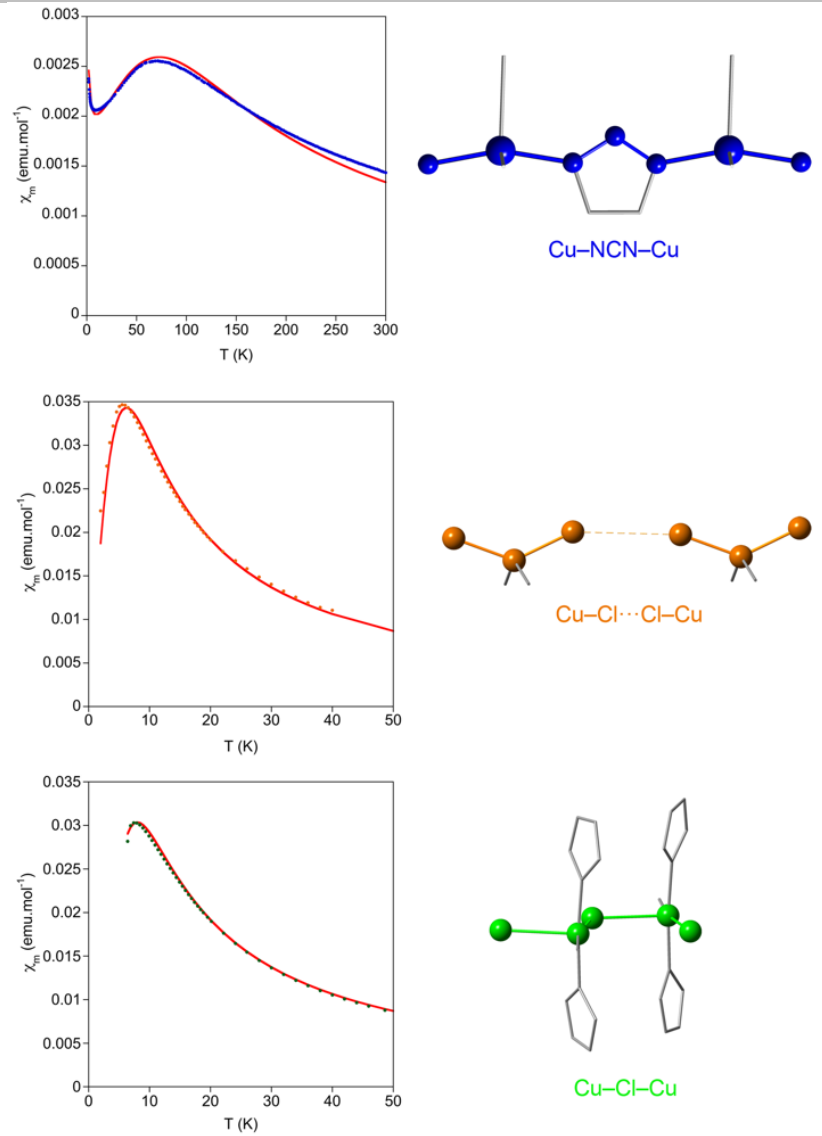

Figure 4. (left) Thermal dependence of the molar magnetic susceptibility $\left(\chi_{M}\right)$ for 1 (blue), 2 (orange) and 3 (green). The red lines correspond the fits (see main text). (right) Different magnetic superexchange paths for each compound.

Due to this rupture of the magnetic path, the $\mathrm{Cu}^{2+}$ ions present in compound 2 only present weak antiferromagnetic interactions (via $\mathrm{Cu}-\mathrm{Cl} \cdots \mathrm{Cl}-\mathrm{Cu}$ interactions, Figure 4), as shown in the $X_{m} v s$. T curve, which exhibits a maximum at $5.6 \mathrm{~K}$. This is in agreement with the constant $\chi_{M} T$ value of $0.46 \mathrm{emu} \cdot \mathrm{K} \cdot \mathrm{mol}^{-1}$, which corresponds well with the expected value for non-interacting $\mathrm{Cu}^{2+}$ ions with spin $1 / 2$ and $\mathrm{g}=$ 2.25 , only decreasing at low temperatures (Figure S2). The magnetic data can be modelled as a linear antiferromagnetic chain of spin $=1 / 2$ interacting weakly with neighbouring chains (via longer $\mathrm{Cu}-\mathrm{Cl} \cdots \mathrm{Cl}-$ $\mathrm{Cu}$ interactions, see Figure S3), leading to a magnetic coupling $\mathrm{J}=-$ $4.9 \mathrm{~cm}^{-1}$ and $\theta=-0.6 \mathrm{~cm}^{-1}$.

The exposure of compound 2 to air causes the release of two equivalents of $\mathrm{HCl}$ with the corresponding structural rearrangement that again modifies the magnetic pathway between the $\mathrm{Cu}^{\prime \prime}$ centers. The polymeric nature of $\mathbf{3}$ differs with that of $\mathbf{1}$ in the nature of the bridging group, which is a chloride atom instead of an imidazolate. The geometry of this bridging $\mathrm{Cl}^{-}$ligand does not facilitate efficient magnetic exchange, since the magnetic orbitals are almost orthogonal. Therefore, the magnetic coupling observed in $\mathbf{3}$ is much weaker than the observed one in compound $\mathbf{1}$, being more similar to 2 . Figure 4 shows a maximum in the $X_{m} v s$. T curve centered at $7.6 \mathrm{~K}$, and Figure $\mathrm{S} 2$ shows a constant $\chi_{\mathrm{M}} \mathrm{T}$ value of $0.44 \mathrm{emu} \cdot \mathrm{K} \cdot \mathrm{mol}^{-1}$, in agreement with the expected value for non-interacting $\mathrm{Cu}^{2+}$ ions with spin $1 / 2$ and 
$g=2.25$, only decreasing at low temperatures. The magnetic data can be modelled as a linear antiferromagnetic chain of spin $=1 / 2$ interacting weakly with neighbouring chains (via hydrogen bonds, see Figure S3), leading to a magnetic coupling $\mathrm{J}=-4.6 \mathrm{~cm}^{-1}$ and $\theta=-1.4 \mathrm{~cm}^{-1}$. Although the changes in the magnetic exchange are only evident at very low temperatures, the substantial changes suffered by the coordination environment of the metal centers upon the solid-gas reaction has allowed us to exploit electron paramagnetic resonance (EPR) spectroscopy to follow the magnetostructural changes at room temperature. Figure 5 shows the room temperature EPR spectra of 1 , $\mathbf{2}$ and $\mathbf{3}$, revealing isotropic spectra for $\mathbf{1}$ and $\mathbf{3}$, with $\mathrm{g}=2.31$ for $\mathbf{1}$, and $\mathrm{g}=2.11$ for 3 , and a tetragonal spectrum for 2 , with $g_{\|}=2.37$ and $g_{\perp}=2.09$ ( $\left.g_{\text {average }}=2.18\right)$. These values are in good agreement with the different coordination environments of the $\mathrm{Cu}$ centres.
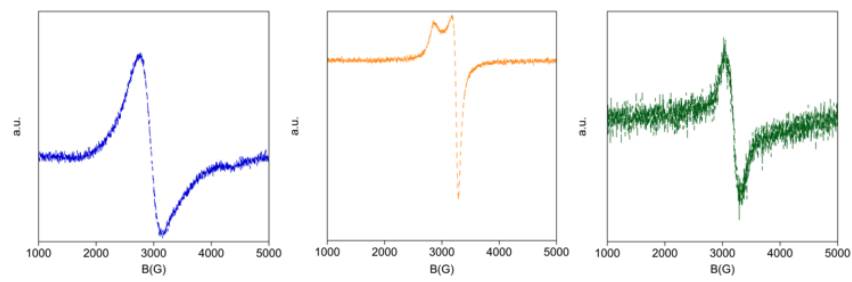

Figure 5. Room temperature X-band EPR spectra of $\mathbf{1}$ (blue), $\mathbf{2}$ (orange) and $\mathbf{3}$ (green).

\section{Conclusions}

Here we have shown a fascinating two-consecutive transformation upon sorption/release of $\mathrm{HCl}$. A series of drastic changes are observed, including modification of coordination geometry, space group, color and dimensionalities. Unequivocal proof has been obtained by single-crystal X-ray diffraction analysis, which is the most powerful method to obtain the detailed structure of a complex before and after the two consecutive structural transformations that take place. In addition, nonporous crystalline materials permit overcoming the challenges to combine magnetic exchange and gas sorption, but this usually results in the loose of single crystallinity, thus hindering the understanding of the magnetostructural changes caused by the vapor. With the exception of some exchangeable solvents directly coordinated to the metal centres, which can be cycled for several species,${ }^{[19]}$ all the reported examples of crystalline transformations in molecular (non-porous) solids occur in a single step, ${ }^{[12]}$ To the best of our knowledge, this is the first report of multiple transformations with rearrangement of molecules in the solid state while preserving the crystalline order at the end of the transformations.

\section{Experimental section}

\section{Materials and methods}

All reagents were commercially available and used without further purification.

Synthesis of $\left[\mathrm{Cu}(\mathrm{im})(\mathrm{Cl})(\mathrm{imH})_{2}\right](1)$. The synthesis is carried out successfully under basic conditions by slow diffusion in a $\mathrm{H}$-tube of methanolic solutions of $\mathrm{CuCl}_{2} \cdot 2 \mathrm{H}_{2} \mathrm{O}(34 \mathrm{mg}, 0.20 \mathrm{mmol}$ in $2 \mathrm{ml}$ of $\mathrm{MeOH}$ ), and imidazole (29mg, $0.43 \mathrm{mmol}$ in $2 \mathrm{ml}$ of $\mathrm{MeOH}$ ) in the presence of $\mathrm{NEt}_{3}(28 \mu \mathrm{l}, 0.2 \mathrm{mmol})$. Laminate-shaped electric blue crystals of 1 were obtained after six weeks in enough quantity for some characterization experiments. The crystal structure was determined by $X$-ray single-crystal diffraction (CCDC1833301), phase purity was established by X-ray powder diffraction (Figure 6a). Anal. calc. $\mathrm{CuC}_{9} \mathrm{H}_{11} \mathrm{~N}_{6} \mathrm{Cl}(302.23 \mathrm{~g} / \mathrm{mol})$ : C, 35.77; H, 3.67; N, $27.81 \%$. Found: C, 35.49; H, 3.60; N, $27.43 \%$.

Synthesis of $\left(\mathrm{imH}_{2}\right)_{2}\left[\mathrm{CuCl}_{4}\right]$ (2). $5 \mathrm{mg}$ of single-crystals from 1 were placed inside a small vial, which was introduced in a larger one containing ca. $10 \mathrm{ml}$ of concentrated aqueous $\mathrm{HCl}(37 \%)$. Exposure of the crystals of 1 to the vapors of $\mathrm{HCl}$ resulted in a change of colour (blue to yellow) clearly observed within a few seconds. The complete conversion to compound $\mathbf{2}$, a crystalline yellow material, occurs in ca. 30 min. A small single crystal suitable for X-ray single crystal diffraction was found (CCDC1833302).

An alternative synthesis to obtain larger quantities of single phase bulk material consists on using the same experimental procedure albeit using $20 \mathrm{mg}$ of crystalline powder 3 (vide infra) as starting material. Exposure of powder from 3 to $\mathrm{HCl}$ vapors results in a change of colour (green to yellow) observed within a few seconds, completing the conversion to compound 2, a crystalline yellow powder, in ca. 30 $\mathrm{min}$. Phase purity was established by $\mathrm{X}$-ray powder diffraction (Figure 6b). Anal. calc. $\mathrm{CuC}_{6} \mathrm{H}_{10} \mathrm{~N}_{4} \mathrm{Cl}_{4}$ (343.53 g/mol): C, 20.98; $\mathrm{H}, 2.93 ; \mathrm{N}$, $16.31 \%$. Found: C, $20.65 ; \mathrm{H}, 2.89$; N, $16.20 \%$.

Exposure of crystals of 1 or $\mathbf{3}$ to dry $\mathrm{HCl}$, generated in situ by dropwise addition of $120 \mathrm{ml}$ of $\mathrm{H}_{2} \mathrm{SO}_{4}$ onto $250 \mathrm{~g}$ of $\mathrm{NaCl}$ and redirected to the corresponding compound, also results in a change of colour (blue or green to yellow).

Synthesis of $\left[\mathrm{CuCl}_{2}(\mathrm{imH})_{2}\right]$ (3). The exposure of single-crystals of 2 to the air at room temperature is accompanied by a color change from yellow to emerald green (compound 3 ). The reaction is completed in six weeks approximately, where crystals suitable for X-ray singlecrystal diffraction were found (CCDC1833300). The conversion can be accelerated by heating 2 during three hours at $90^{\circ} \mathrm{C}$.

Alternatively, larger quantities of single phase bulk material can be obtained by mechanochemical procedures. ${ }^{[38]} 171 \mathrm{mg}(1 \mathrm{mmol})$ of $\mathrm{CuCl}_{2} \cdot 2 \mathrm{H}_{2} \mathrm{O}$ and $136 \mathrm{mg}$ ( $2 \mathrm{mmol}$ ) of imidazole were forcefully ground in an agate mortar, resulting in the formation of $\mathbf{3}$ as a green polycrystalline powder. Phase purity was established by $\mathrm{X}$-ray powder diffraction (Figure 6c). Anal. calc. $\mathrm{CuC}_{6} \mathrm{H}_{8} \mathrm{~N}_{4} \mathrm{Cl}_{2}(270.61 \mathrm{~g} / \mathrm{mol}$ ): C, $26.63 ; \mathrm{H}, 2.98 ; \mathrm{N}, 20.70$ \%. Found: C, 26.55; H, 2.99; N, $20.73 \%$. 


\begin{tabular}{|c|c|c|c|}
\hline & 1 & 2 & 3 \\
\hline Empirical formula & $\mathrm{C}_{9} \mathrm{H}_{11} \mathrm{~N}_{6} \mathrm{ClCu}$ & $\mathrm{C}_{12} \mathrm{H}_{20} \mathrm{~N}_{8} \mathrm{Cl}_{8} \mathrm{Cu}_{2}$ & $\mathrm{C}_{12} \mathrm{H}_{16} \mathrm{~N}_{8} \mathrm{Cl}_{4} \mathrm{Cu}_{2}$ \\
\hline Formula weight & 302.23 & 687.04 & 540.21 \\
\hline Crystal colour & Blue & Yellow & Green \\
\hline Crystal size $(\mathrm{mm})$ & $0.20 \times 0.12 \times 0.10$ & $0.05 \times 0.04 \times 0.04$ & $0.05 \times 0.04 \times 0.03$ \\
\hline Crystal system & Orthorhombic & Triclinic & Orthorhombic \\
\hline Space group, $Z$ & $P m n 2_{1}, 2$ & $P-1,2$ & $\mathrm{Cmc} 2_{1}, 2$ \\
\hline$a(\AA)$ & $13.6857(3)$ & $7.7600(4)$ & $13.0117(6)$ \\
\hline$b(\AA)$ & $6.10160(10)$ & $11.2878(7)$ & $10.7563(4)$ \\
\hline$c(\AA)$ & $7.14750(10)$ & $14.8140(6)$ & $6.6877(3)$ \\
\hline$\alpha\left({ }^{\circ}\right)$ & 90 & $85.087(4)$ & 90 \\
\hline$\beta\left({ }^{\circ}\right)$ & 90 & $88.670(3)$ & 90 \\
\hline$Y\left({ }^{\circ}\right)$ & 90 & $86.307(4)$ & 90 \\
\hline$V\left(\AA^{3}\right)$ & $596.850(18)$ & $1289.95(12)$ & $936.00(7)$ \\
\hline Density $\left(\mathrm{mg} \cdot \mathrm{m}^{-3}\right)$ & 1.682 & 1.769 & 1.920 \\
\hline Wavelength $(\AA)$ & 0.71073 & 0.71073 & 0.71073 \\
\hline Temperature $(\mathrm{K})$ & $120(2)$ & $120(2)$ & $120(2)$ \\
\hline$\mu(\mathrm{Mo}-\mathrm{K} \alpha)\left(\mathrm{mm}^{-1}\right)$ & 2.039 & 2.495 & 2.858 \\
\hline $2 \theta$ range $\left({ }^{\circ}\right)$ & $5.954-50.054$ & $6.578-50.054$ & $6.092-50.022$ \\
\hline Reflns collected & 23454 & 35873 & 1319 \\
\hline Independent reflns $\left(R_{\text {int }}\right)$ & $1114(0.0311)$ & $4550(0.1414)$ & $609(0.0305)$ \\
\hline Reflns used in refinement, $n$ & 1114 & 4550 & 609 \\
\hline L.S. parameters, $p$ & 88 & 271 & 57 \\
\hline No. of restraints, $r$ & 1 & 0 & 1 \\
\hline$R 1(F)^{\mathrm{a}} I>2.0 \sigma(I)$ & 0.0148 & 0.0444 & 0.0287 \\
\hline$w R 2\left(F^{2}\right),{ }^{\mathrm{b}}$ all data & 0.0392 & 0.0891 & 0.0604 \\
\hline$S\left(F^{2}\right){ }^{c}$ all data & 1.158 & 0.943 & 1.089 \\
\hline
\end{tabular}

[a] $R 1(F)=\Sigma\left(\left|F_{o}\right|-\left|F_{c}\right|\right) / \Sigma\left|F_{o}\right| ;[b] w R 2\left(F^{2}\right)=\left[\Sigma w\left(F_{o}^{2}-F_{c}^{2}\right)^{2} / \Sigma w F_{o}^{4}\right]^{1 / 2} ;[\mathrm{c}] S\left(F^{2}\right)=\left[\Sigma w\left(F_{o}^{2}-F_{c}^{2}\right)^{2} /(n+r-p)\right]^{1 / 2}$

\section{Magnetic measurements}

Magnetic susceptibility measurements were carried out on polycrystalline samples with a Quantum Design MPMS-XL-5 SQUID susceptometer. The susceptibility data were all collected at $1 \mathrm{~K} \cdot \mathrm{min}^{-1}$, with an applied field of $0.1 \mathrm{~T}$.

\section{EPR measurements}

EPR spectroscopy was recorded with a Bruker ELEXYS E580 spectrometer operating in the $\mathrm{X}$-band $(9.47 \mathrm{GHz})$.

\section{Single-crystal X-ray diffraction}

A single crystal of each compound (1, 2 and 3 ) was mounted on a on a cryoloop using a viscous hydrocarbon oil to coat the crystal. Due to technical issues, it has not been possible to measure the same single crystal upon the consecutive transformations. X-ray data were collected at $120 \mathrm{~K}$ on a Supernova diffractometer equipped with a graphite-monochromated Enhance (Mo) X-ray Source $(\lambda=0.71073$ $\AA$ ). The program CrysAlisPro, Oxford Diffraction Ltd., was used for unit cell determinations and data reduction. Empirical absorption correction was performed using spherical harmonics, implemented in the SCALE3 ABSPACK scaling algorithm. The crystal structures were solved and refined against all $F^{2}$ values by using the SHELXTL and Olex 2 suite of programs. ${ }^{[49,50]}$ Non-hydrogen atoms were refined anisotropically and hydrogen atoms were placed in calculated positions that were refined using idealized geometries (riding model) and assigned fixed isotropic displacement parameters. A summary of the data collection and structures refinements is provided in Table 1. CCDC-1833300, -1833301 and -1833302 contains the supplementary crystallographic data for this paper. This data can be obtained free of charge from The Cambridge Crystallographic Data Centre via www.ccdc.cam.ac.uk/data_request/cif. 


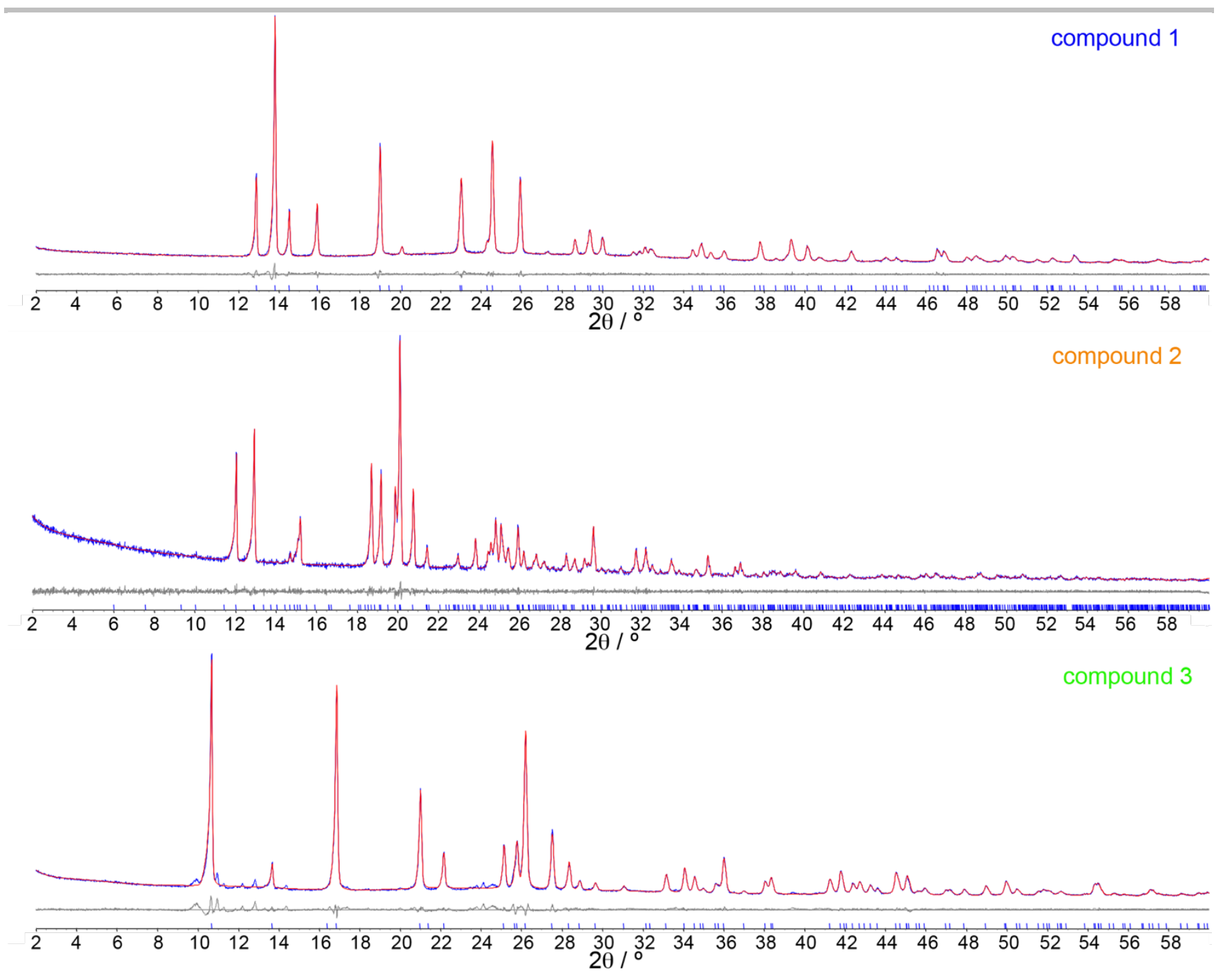

Figure 6. Observed (blue) and calculated (red) profiles and difference plot [ $\left.\left(\mathrm{l}_{\mathrm{obs}}-\mathrm{I}_{\text {calcd }}\right)\right]$ (grey) of the Pawley refinements of compounds 1 (top), 2 (middle), and 3 (bottom). (20 range $2-60^{\circ}$; maximum resolution $1.54 \AA$ ).

\section{X-ray powder diffraction}

Polycrystalline samples of 1, $\mathbf{2}$ and $\mathbf{3}$ were lightly ground in an agate mortar and pestle and filled into $0.5 \mathrm{~mm}$ borosilicate capillary prior to being mounted and aligned on an Empyrean PANalytical powder diffractometer, using $\mathrm{Cu} \mathrm{Ka}$ radiation $(\lambda=1.54056 \AA)$. For each compound, two repeated measurements were collected at room temperature $\left(2 \theta=2-60^{\circ}\right)$ and merged in a single diffractogram. Pawley refinements ${ }^{[51]}$ were performed using the TOPAS computer program, ${ }^{[52]}$ and revealed an excellent fit to a one-phase model for compounds $1\left(R_{\mathrm{wp}}=0.0380\right.$; GOF = 1.370, Figure 6a), $2\left(R_{\mathrm{wp}}=\right.$ $0.0575 ; \mathrm{GOF}=1.162$, Figure $6 \mathrm{~b})$, and $3\left(R_{w p}=0.0617 ; \mathrm{GOF}=2.505\right.$, Figure $6 \mathrm{c}$ ). In all cases the unit cell obtained from the Pawley refinement is consistent with those obtained by single crystal diffraction (see Supporting Table S1).

\section{Thermogravimetric analysis}

Thermogravimetric analysis of $\mathbf{1}$ and $\mathbf{3}$ were carried out with a TA instruments TGA 550 apparatus in the $25-600{ }^{\circ} \mathrm{C}$ temperature range under a $5{ }^{\circ} \mathrm{C} \cdot \mathrm{min}^{-1}$ scan rate and an air flow of $40 \mathrm{~mL} \cdot \mathrm{min}^{-1}$.
Thermogravimetric analysis of 2 cannot be performed due to incompatibilities of $\mathrm{HCl}$ release with the equipment.

\section{Acknowledgements}

The work has been supported by the European Union (ERC-2016CoG 724681-S-CAGE) and the Spanish MINECO (Unit of Excellence María de Maeztu MDM-2015-0538, projects CTQ2014-59209-P and CTQ2017-89528-P). G.M.E. thanks MINECO for a Ramón y Cajal fellowship. J.L.-C. acknowledges the University of Valencia for an "Atracció de Talent" grant. N.C.G. thanks the Generalitat Valenciana for a VALi+d predoctoral fellowship. J. M. Martínez-Agudo and G. Agustí, from the University of Valencia, are gratefully acknowledged for performing the magnetic measurements.

\section{Keyworkds}

solid-gas reactions; magnetism; coordination polymers

\section{References}

[1] G. Maurin, C. Serre, A. Cooper, G. Férey, Chem. Soc. Rev. 2017, 46, 
3104-3107.

[2] B. F. Hoskins, R. Robson, J. Am. Chem. Soc. 1989, 111, 5962-5964.

[3] B. F. Hoskins, R. Robson, J. Am. Chem. Soc. 1990, 112, 1546-1554.

[4] P. Z. Moghadam, A. Li, S. B. Wiggin, A. Tao, A. G. P. Maloney, P. A. Wood, S. C. Ward, D. Fairen-Jimenez, Chem. Mater. 2017, 29, 2618 2625 .

[5] E. Coronado, G. Mínguez Espallargas, Chem. Soc. Rev. 2013, 42, 15251539.

[6] L. E. Kreno, K. Leong, O. K. Farha, M. Allendorf, R. P. Van Duyne, J. T. Hupp, Chem. Rev. 2012, 112, 1105-1125.

[7] E. Coronado, M. Giménez-Marqués, G. Mínguez Espallargas, F. Rey, I. J. Vitórica-Yrezábal, J. Am. Chem. Soc. 2013, 135, 15986-15989.

[8] N. Calvo Galve, M. Giménez-Marqués, M. Palomino, S. Valencia, F. Rey, G. Mínguez Espallargas, E. Coronado, Inorg. Chem. Front. 2016, 3, 808-813.

[9] M. Giménez-Marqués, N. Calvo Galve, M. Palomino, S. Valencia, F. Rey, G. Sastre, I. J. Vitórica-Yrezábal, M. Jiménez-Ruiz, J. A. Rodríguez-Velamazán, M. A. González, G. Mínguez Espallargas, E. Coronado, Chem. Sci. 2017, 8, 3109-3120.

[10]Z. Arcís-Castillo, F. J. Muñoz-Lara, M. C. Muñoz, D. Aravena, A. B. Gaspar, J. F. Sánchez-Royo, E. Ruiz, M. Ohba, R. Matsuda, S. Kitagawa, J. A. Real, Inorg. Chem. 2013, 52, 12777-83.

[11]G. Mínguez Espallargas, E. Coronado, Chem. Soc. Rev. 2018, 533-557.

[12] J. J. Vittal, H. S. Quah, Coord. Chem. Rev. 2017, 342, 1-18.

[13] G. Aromí, C. M. Beavers, J. Sánchez Costa, G. A. Craig, G. Mínguez Espallargas, A. Orera, O. Roubeau, Chem. Sci. 2016, 7, 2907-2915.

[14] J. L. Atwood, L. J. Barbour, A. Jerga, B. L. Schottel, Science (80-. ). 2002, 298, 1000-1002.

[15]E. Coronado, M. Giménez-Marqués, G. Mínguez Espallargas, L. Brammer, Nat. Commun. 2012, 3, 828 .

[16]H. M. Mande, P. S. Ghalsasi, Sci. Rep. 2015, 5, 1-8.

[17] L. Z. Cai, X. M. Jiang, Z. J. Zhang, P. Y. Guo, A. P. Jin, M. S. Wang, G. C. Guo, Inorg. Chem. 2017, 56, 1036-1040.

[18] C. Bin Tian, Y. H. Han, Z. Z. He, S. W. Du, Chem. - A Eur. J. 2017, 23, 767-772.

[19] S. Rodríguez-Jiménez, H. L. C. Feltham, S. Brooker, Angew. Chem. Int. Ed. 2016, 55, 15067-15071.

[20] A. Lennartson, P. Southon, N. F. Sciortino, C. J. Kepert, C. Frandsen, S. Mørup, S. Piligkos, C. J. McKenzie, Chem. - A Eur. J. 2015, 21, 1606616072 .

[21] J. S. Costa, S. Rodríguez-Jiménez, G. A. Craig, B. Barth, C. M. Beavers, S. J. Teat, G. Aromí, J. Am. Chem. Soc. 2014, 136, 3869-3874.

[22] B. Li, R. J. Wei, J. Tao, R. Bin Huang, L. S. Zheng, Z. Zheng, J. Am. Chem. Soc. 2010, 132, 1558-1566.

[23] R. J. Wei, J. Tao, R. Bin Huang, L. S. Zheng, Inorg. Chem. 2011, 50, 8553-8564.

[24]W. Huang, F. Shen, M. Zhang, D. Wu, F. Pan, O. Sato, Dalt. Trans. 2016 $45,14911-14918$

[25] P. Kar, M. Yoshida, Y. Shigeta, A. Usui, A. Kobayashi, T. Minamidate, N. Matsunaga, M. Kato, Angew. Chem. Int. Ed. 2017, 56, 2345-2349.

[26] M. Cibian, G. S. Hanan, Chem. - A Eur. J. 2015, 21, 9474-9481.

[27]D. Q. Wu, D. Shao, X. Q. Wei, F. X. Shen, L. Shi, D. Kempe, Y. Z. Zhang, K. R. Dunbar, X. Y. Wang, J. Am. Chem. Soc. 2017, 139, 11714 11717.
[28] J. Vallejo, E. Pardo, M. Viciano-Chumillas, I. Castro, P. Amorós, M. Déniz, C. Ruiz-Pérez, C. Yuste-Vivas, J. Krzystek, M. Julve, F. Lloret, J. Cano, Chem. Sci. 2017, 8, 3694-3702.

[29]B. K. S. Lundberg, B. Sjöberg, R. Söderquist, A. Haaland, Å. Pilotti, Acta Chem. Scand. 1972, 26, 3902-3912.

[30] J. Lin, Y. Zheng, Z. Kristallogr. NCS. 2004, 219, 431-432.

[31] G. Mínguez Espallargas, A. J. Florence, J. van de Streek, L. Brammer, CrystEngComm 2011, 13, 4400-4404.

[32]I. J. Vitorica-Yrezabal, R. A. Sullivan, S. L. Purver, C. Curfs, C. C. Tang, L. Brammer, CrystEngComm 2011, 13, 3189-3196.

[33] G. Mínguez Espallargas, J. Van De Streek, P. Fernandes, A. J. Florence, M. Brunelli, K. Shankland, L. Brammer, Angew. Chem. Int. Ed. 2010, 49, 8892-8896.

[34] G. Mínguez Espallargas, M. Hippler, A. J. Florence, P. Fernandes, J. Van De Streek, M. Brunelli, W. I. F. David, K. Shankland, L. Brammer, J. Am. Chem. Soc. 2007, 128, 15606-15614.

[35] G. Mínguez Espallargas, L. Brammer, J. Van De Streek, K. Shankland, A. J. Florence, H. Adams, J. Am. Chem. Soc. 2006, 128, 9584-9585.

[36] S. M. Fellows, T. J. Prior, Cryst. Growth Des. 2017, 17, 106-116.

[37]H. Li, F. Guo, M. Kou, A. Famulari, Q. Fu, J. Marti-Rujas, Inorg. Chem. 2017, 56, 6584-6590.

[38]C. J. Adams, M. A. Kurawa, M. Lusi, A. G. Orpen, CrystEngComm 2008, 10, 1790-1795

[39] L. Brammer, E. A. Bruton, P. Sherwood, Cryst. Growth Des. 2001, 1, $277-290$.

[40]C. J. Adams, M. F. Haddow, M. Lusi, A. G. Orpen, Proc. Natl. Acad. Sci. 2010, 107, 16033-16038.

[41] A. N. Khlobystov, N. R. Champness, C. J. Roberts, S. J. B. Tendler, C. Thompsom, M. Schröder, CrystEngComm, 2002, 4, 426-431.

[42] X. Cui, A. Khlobystov, X. Chen, D. Marsh, A. Blake, W. Lewis, N. Champness, C. Roberts, M. Schröder, Chem. - A Eur. J. 2009, 15, 88618873 .

[43] C. J. Adams, H. M. Colquhoun, P. C. Crawford, M. Lusi, A. G. Orpen, Angew. Chem. Int. Ed. 2007, 46, 1124-1128.

[44] C. J. Adams, M. A. Kurawa, A. G. Orpen, Inorg. Chem. 2010, 49, 10475-10485.

[45]F. Guo, H. Shao, Q. Yang, A. Famulari, J. Martí-Rujas, CrystEngComm 2014, 16, 969-973.

[46]F. Guo, M.-Q. Zhang, A. Famulari, J. Martí-Rujas, CrystEngComm 2013, $15,6237-6243$.

[47]B. K. S. Lundberg, B. Sjöberg, R. Söderquist, A. Haaland, Å. Pilotti, Acta Chem. Scand. 1972, 26, 3977-3983.

[48]Y. Q. Tian, C. X. Cai, X. M. Ren, C. Y. Duan, Y. Xu, S. Gao, X. Z. You, Chem. - A Eur. J. 2003, 9, 5673-5685.

[49] G. M. Sheldrick, Acta Crysta llogr. Sect. A 2008, 64, 112-122.

[50] O. V. Dolomanov, L. J. Bourhis, R. J. Gildea, J. A. K. Howard, H. Puschmann, J. Appl. Crystallogr. 2009, 42, 339-341.

[51] G. S. Pawley, J. Appl. Crystallogr. 1981, 14, 357-361.

[52] A. A. Coelho, TOPAS-Academic, Version 4.1, 2007, see http://www.topas-academic.net. 
Table of contents

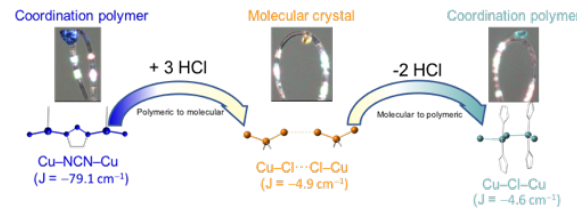

Crystal clear. Modification of the magnetic properties in the solid-state is achieved in non-porous molecular crystals through incorporation and extrusion $\mathrm{HCl}$ gas molecules. 